\title{
On Vocabulary Learning Strategies of Chinese Non-English Majors
}

\author{
Zhiqiang Zhang ${ }^{1}$, Jie $\mathrm{Lu}^{2}$
}

Associate professor of Shandong University of Technology, is mainly engaged in College English teaching and research,

University of Technology, Zibo, China

\begin{abstract}
The paper attempts to investigate the overall pattern of English vocabulary learning beliefs and strategies used by some Chinese non-English major students, and further investigate the correlation between students' vocabulary learning beliefs, vocabulary learning strategies, and the scores on a vocabulary size (VS) test and an in-depth vocabulary knowledge (DVK) test. Three instruments are used to gather data for this study: Nation's Vocabulary Levels Test (1990), Read's Word Association Format (1998), and a questionnaire on VLS adapted from Gu and Johnson's
\end{abstract} (1996). The questionnaires and the two tests are administered to college students majoring in science from the Shandong University of Technology. Descriptive statistics and correlation analysis are conducted to analyze the data collected. The results of this study show that: Firstly, most learners hold the belief that words should be learned in context and use while the belief that words should be memorized is not popular. Most students believe that learners should not only make efforts to enlarge their vocabulary size but also pay sufficient attention to various aspects of vocabulary knowledge. The learning beliefs do have an influence on their achievement in vocabulary learning. Secondly, students employ a wide range of VLS in their foreign language learning at meta-cognitive, cognitive and social/affective levels, but the frequency of overall VLS use is not high. In terms of the three categories of VLS, the most frequently used one is the cognitive strategy, and the least frequently used one is the social/effective strategy, with the meta-cognitive strategy in between. The students' strategy use is generally the result of their previous learning experience, the influence of their teachers' teaching methods, traditional Chinese culture, oriental students' characters and the specific learning environment in China. Finally, the results indicate that most strategies are significantly correlated with the VS and DVK scores. At meta-cognitive level, plan to make \& plan to implement strategies, learner autonomy strategies, and reviewing \& testing strategies have a significant positive correlation with the two scores. Selective attention strategies have a significant positive correlation with the DVK scores. At the cognitive level, guessing strategies and note-taking strategies have a significant positive relationship with both the scores on VS and DVK tests. Dictionary use strategies have a significant positive correlation with the DVK scores.

Keywords-Vocabulary learning strategies; Vocabulary size ; Depth of vocabulary knowledge ; Correlation.

\section{INTRODUCTION}

1.1 The importance of vocabulary learning in second language acquisition

Vocabulary learning is an important aspect of second language acquisition. Wilkins (1972:9-10) states, "While without grammar very little can be conveyed, without vocabulary nothing can be conveyed."McCarthy (1990:Viii) also states "No matter how well the student learns the grammar, no matter how successfully the sounds of L2 are mastered, without words to express a wide range of meanings, communication in L2 just cannot happen in any 
mean ingful way ". It is widely recognizable that the mastery of vocabulary is an essential component of second language and foreign language learning. It plays a vital role in all aspects of language learning, including listening, speaking, reading, writing and translation. Therefore, learners must learn vocabulary well in order to become proficient in L2 or FL acquisition.

\subsection{The necessity to study vocabulary learning strategies}

Since the 1990s there has been a marked shift from a predominantly teaching-oriented perspective to a learner-focused orientation. The emphas is has been placed on helping learners take more responsibility for meeting their own language learning needs. The research into learning strategies is due to two main motivations. One desire is to describe the learning process and so better understand the psychological processes by which learners 'interlanguage develop over time and in response to target language input. Another desire is toassist learners to develop appropriate and effective learning strategies so that their language learning goals are reached more quickly. More and more researchers have agreed that the success of language learning depends mainly on learners and their learning strategies. It is commonly accepted that if learners are aware of and proficient in the use of a wide range of learning strategies, their languagelearning will be greatly facilitated. There is a lot of evidence that the use of learning strategies is closely related to learningachievement. Sincevocabulary learning is an indispensable part and the foundation of language learning, it is necessary to conduct further studies concerning vocabulary learning strategy.

\subsection{The purpose of the thesis}

This paper is aimed to investigatethe overall pattern of English vocabulary learning beliefs and strategies adopted by some Chinese non-English major students. The paper also tries to find the correlation between the students' vocabulary learning beliefs, vocabulary learning strategies, and the scores of a vocabulary size (VS) test and an in-depth vocabulary knowledge (DVK) test.
I choose this topic mainly because of the two reasons.Firstly, vocabulary learning remains the major problem for most Chinesecollegestudents. Before studying in college, they have learned most of the grammatical knowledge in the English language, but their vocabulary is confined to limited high-frequency words. According to the basic requirement for non-English major students, they are required to learn 4,200 receptive words and their related phrases or expressions, among which 2500 are productive vocabulary. According to the advanced requirement, students are required to learn 5,500 receptive words and their related phrases and expressions, among which 3,000 words are productive words. Owing to the large a mount of words to be mastered and the various aspects involving in knowing a word, students will meet great difficulty with vocabulary learning. Therefore, more help and guidance should be given to the students in this field. Secondly, researches conducted in the western countries cannot give a true situation as to how Chines estudents' e mploy vocabulary learning strategies in their language learning. Most of them investigate how the foreign students study another Indo-Europeanlanguage and some of them study the effectiveness of some specific vocabulary learning strategies. However, the learning environment in China is quite different from that of the western countries. What are effective with the western learners may not apply to the Chinesestudents. On the other hand, although there are some empirical studies concerning vocabulary learning strategies in China, the results of these studies are not in agreement with each other, owing to different subjects, objective, methodologies, classifications of vocabulary learning strategies. In addition, most of the researches are involved in the quantitative dimension of vocabulary learning. In this study, whileexamin ing the state of the students' vocabulary knowledge, both quantity and quality are included. It is expected that this study will provide some practical information to both college students and college English teachers. The students will be clear about the situation of their strategy use; the correlation between 
vocabulary learning beliefs, strategy use and their actual achievement on VS and DVK tests, so that they can make some adjustment consciously to facilitate their future vocabulary learning. Meanwhile, the teachers may also get some useful information from this paper so that they can give their students more effective help and guidance.

\section{RESEARCH METHODOLOGY}

Thispaper provides a description of the methods used in this study, which include the objectives, the subjects, the instruments used for data collection, and the statistical procedures to analyze the data gathered.

\subsection{Objectives}

The present study aims to answer the following questions: First, what is the overall pattern of vocabulary learning beliefs and strategies adopted by some non-English major students? Second, what is the relationship between vocabulary learning strategies adopted by the students and the scores on a vocabulary size test and in-depth vocabulary knowledge test?

\subsection{Participants}

Participants of the study are 98 third-year non-English majors, 60 males and 38 females, chosen from four parallel classes of Shandong University of Technology. The subjects involved are from different departments: Life Science, Physics, Chemistry and Materials Science. By the time the study is conducted, they have learned English for at least six years in high school and for about three years in college. Two-thirds of them have passed CollegeEnglishTest （Band 4) . Aftere xamin ing each partic ipant's questionnaire and test papers carefully, four of them are found invalid and thus eliminated, leaving the actual number of 94 participants.

\subsection{Instruments}

Three instruments are used to gather data for this study: a vocabulary size (VS) test, a depth-of-vocabulary-knowledge (DVK) test, and a questionnaire on vocabulary learning strategies. The flowing is a brief description of each instrument.

\subsubsection{Test on vocabulary size(VS)}

Nation's (1990) Vocabulary Levels Test (VLT) is adopted in this paper to test the students' vocabulary size. Theoriginal measure is composed of five parts: the 2000-word level, the 3000-word level, the 5000-word level, the university word level, and the 10,000-word level. The 2000-word and 3000-word levels contain high-frequency words. The 5,000-word level is a boundary level between the high-frequency level and low-frequency level; the university word level consists of words frequently appearing in university textbooks, which does not represent a frequency level; and the 10,000-word level covers the low-frequency words. The significance of the vocabulary level test is that it is useful to view vocabulary of English as consisting of a series of levels based on frequency of occurrence. Each word level consists of five groups, which consists of six words to be matched to three definitions. The test taker is required to match the three definitions with three of the six words provided by writing the correspondingnumbers of the words beside its definition. The Vocabulary Levels Test has been widely accepted by many language researchers (e.g. Laufer, 1992) and proved to be a valid test for breadth of vocabulary knowledge.

Nation (1990) argues that this format with unequal number of words anddefinitions minimizes the chances of guessing correctly and tests a large number of words within a short period of time. All the items in each group belong to the same word class in order to avoid giving any grammatical clues as to the correct definition. Moreover, all the items in each group are not related in meaning, thus the test intends to measure the testee's word knowledge, without requiring them to distinguish between semantically related words (Read, 2000). According to the College English Teaching Syllabus (revised version), the requirements for students can be divided intotwo: the basic require ment for CET-4 and the higher requirement for CET-6. According to the basic requirement, students are required to learn 4,200 receptive words and their re lated phrases or expressions, among which 
2500 are productive vocabulary. According to the advanced requirement, students are required to learn 5,500 receptive words and the related phrases and expressions, among which 3,000 words are productive words. Therefore, to fit the student's actual vocabulary level, only the first four word frequency levels of Nation's Vocabulary Levels Test are used to test the participants' vocabulary size. In scoring, the answers are scored as correct or incorrect. Each correct answer is given one point. There are four sections in the test, each of which contains 18 items. Therefore, the maximum score is 72 points.

\subsubsection{Test on depth of vocabulary knowledge (DVK)}

The Word Association Format (WAF) developed by Read (1998) is adapted to asses s the students' in-depth vocabulary knowledge. Most of the stimulus adjectives are high frequency andacademic vocabulary. This format has been proved to be a valid and reliable measure of depth of vocabulary knowledge. Since three words in the original WAF is beyond the level of the students investigated, a slight change is made. Therefore, the test paper used in this study contains 40 items, of which 37 are orig inal WAF ite ms and three words are newly developed ones. The reliability of the version used in this paper is 0.91. Each DVK itemconsists of one stimulus word, which is an adjective, and two boxes, each containing four words. A mongthe four words in the left box, one to three words can be synonymous to one aspect of or the whole meaning of the stimu lus word, while among the four words in the right box there can be one to three words that collocate with the stimu lus word. Each item always has four correct choices. However, these choices are not evenly spread. There are three possible situations: (1) the left and right boxes both contain two correct answers;(2) the left box contains one correct choice, while the right box contains three correct answers and; (3) the left box contains three correct answers while the right box contains one correct choice. The arrangement effectively reduces the chances of guessing. Although the DVK taps only knowledge of adjectives, nouns are indirectly tested as well because the design of the measure requires the identification of nouns that collocate with the adjectives tested. In scoring, word correctly chosen is granted one point. The maximum possible score is 160 for the 40 ite ms. No penalty is given for providing the incorrect answers.

\subsubsection{Questionnaire design}

The present study uses a questionnaire to collect date about the vocabulary learning strategies used by the participants and the vocabulary learning beliefs they hold. Thequestionnaire is adapted from Gu and Johnson's (1996) because it is a relatively comprehensive one that reflects previous quantitative and qualitative research. In order to have a more comprehensive picture of the students' vocabulary learning strategies, social /affective strategies and some additional vocabulary learning strategies are added to the present questionnaire and some changes are made about the items of the original questions. With regard to vocabulary learning beliefs, some questions concerning in-depth vocabulary knowledge are added. The reliability coefficient of the questionnaire is 0.90 .

Of the whole questionnaire, 10 items deal with the participants' general beliefs on vocabulary learning, which are in intended to find out the students' ideas on the nature of vocabulary learning. In the questionnaire, 94 items concern vocabulary learning strategies. In $\mathrm{Gu}$ and Johnson's'questionnaire, this part contains 91 English vocabulary learning behaviors representing two dimensions: Meta-cognitive regulation and cognitive strategies. In this study a total of 94 vocabulary learning strategies are identified, representing three dimensions: meta-cognitive strategies, cognitives trategies, and social/affective strategies. The following will indicate the classification in detail.

Meta-cognitive strategies consist of plan making \& plan implementing, selective attention, learner autonomy, and reviewing \& testing. Plan making \& plan implementing (6 items) involves making plan for both the quality and quantity of vocabulary study and the implementing of the plan. Selective attention ( 6 ite ms) measures the students ' ability to identify importantwords, as well as important aspects of word knowledge. Learner autonomy (6 ite ms) inquires about 
students' main resources of vocabulary learning, their opportunities to practice using vocabulary and their preference for vocabulary learning activities. Reviewing \& testing (6 items), inquires about how often and in what way the students review what they have learned and are tested on what they have learned.

Cognitive Strategies fall into four subcategories: memorization, guessing, dictionary use and note taking. Memorization (30) includes six subcategories: repetition, association, imagery, word formation, grouping and contextualization. Repetition falls into oral repetition, visual repetition or combined form of repetition to memorize new words. Association is concerned with whether students try to learn new words by building phonological, morphological or semantic association between the new words and the ones already learned by using their Chinese or English knowledge. Imagery is concerned with whether students create mental images in mind or act out a word in order to facilitate memorization. Word formation strategies address the question of whether students memorize new words by deliberately learning word formation rules and apply these rules in their vocabulary learning. Grouping strategy asks the students if they group the new items into various categories based on semanticlinks, such as synonymy/antonymy, hyponymy and different semantic fields.

Guessing strategy consists of 9 items, inquiring if the students guess the meaning of an unknown word in context by using background knowledge or linguistics cues. The 12 items under dictionary use ask the students for what purposes they consult a dictionary, and whether they have mastered the looking-up strategies. This category can be further divided into dictionary use for reading comprehension, looking up strategies, and elaborate use of dictionary for vocabulary learning.

Note taking strategy ( 8 items) inquires what kinds of notes students take when they learn vocabulary, meaning-oriented or usage-oriented. Meaning-orientedstrategies involve taking down the Eng lishwords, its Chinese equivalents, its explanations, or its English synonyms and antonyms. Usage-oriented strategies involve taking down the information related with the words, such as part of speech, grammaticalinformation, collocations and sample sentences etc.

Social/ affective strategies include two parts: social activities and affective control. The 6 items under affective control investigate whether students can concentrate on their learning, possess self-confidence, and encourage themselves when faced with difficulties. Socialactivities, consisting of 5 items, inquire the students if they seek opportunities to talk with foreigners, classmates or roommates in English, write English letters or E-mails.

The present questionnaire adopts a 5-ponit scale rating system. Each question is provided with five alternative choices which show the different frequency of the use of vocabulary learning strategies ranging from "absolutely disagree" to "absolutely agree". Different scores are given to the 5-scale rating system: "1"stands for "absolutely disagree", "2"stands for "basically disagree", “3"stands for "hard to say", which means "sometimes yes and sometimes no", “4"stands for "basically agree", "5"stands for "absolutely agree". Students are required to choose one of them accord ing to what they really do rather than what they think they should do.

\subsection{Data Collection}

The survey was conducted in March of 2018 in regular English classes. Before the test papers on vocabularysize, the test papers on in-depth vocabulary knowledge, and the questionnaires on vocabulary learning strategies were distributed to the participants, some explanatory remarks were made to inform the participants of the purpose and the contents of the two tests and questionnaire and call their attention to the instruction of different parts to ensure that their responses would be pertinent to the requirement.

\subsection{Date analysis}

SPSS 11.5 for windows is used to process and analyze the data collected from the questionnaire, the vocabulary size test and in-depth vocabulary knowledge test. Firstly, all the 
data is put into the program for analysis and statistic description of vocabulary learning beliefs and strategies of the participants is obtained. Secondly, correlationanalys is is performedbetween the independent variables (the beliefs and strategies) and the dependent variables (the scores on the two vocabulary tests) to see in what ways they are correlated.

\section{RESULTS AND FINDINGS}

3.1The overall pattern of vocabulary learning beliefs and VLS

In this part, we will try to find out (1) the students' beliefs about vocabulary learning (2) the overall pattern of their VLS use at meta-cognitive, cognitive and social affective levels. Mean score and standard deviation of vocabulary learning beliefs and strategies used by the students are calculated by using SPSS software. As the five-point scale system is adopted in the study, a mean score larger than 3.0000 indicates that the item in the questionnaire is frequently used by the students while the strategy with the mean score smaller than 3.0000 indicates the item is seldom used by the students.

\subsubsection{Vocabulary learning beliefs}

Just as Table 3.1 showed, most subjects hold the belief that words should be learned in context and use while the belief that words should be memorized is not popular. As to what should be placed in the first place, to enlarge vocabulary knowledge or to pay more attention to deep knowledge of lexical items, the later enjoys more popularity. Most students believe that learners should not only make efforts to enlarge their vocabulary size but also pay sufficient attention to various aspects of vocabulary knowledge, the usage, the grammatical features, the collocations and so on.

Table.3.1: The beliefs on vocabulary learning

\begin{tabular}{|c|c|c|c|}
\hline Beliefs & $\begin{array}{l}\mathrm{N} \text { of } \\
\text { items }\end{array}$ & $\begin{array}{l}\text { Mea } \\
\mathrm{n}\end{array}$ & SD \\
\hline $\begin{array}{l}\text { Words should be learned in } \\
\text { context \& use }\end{array}$ & 3 & $\begin{array}{l}3.45 \\
12\end{array}$ & $\begin{array}{l}.711 \\
34\end{array}$ \\
\hline $\begin{array}{l}\text { Words should be } \\
\text { memorized }\end{array}$ & 3 & $\begin{array}{l}2.45 \\
23\end{array}$ & $\begin{array}{l}.696 \\
42\end{array}$ \\
\hline
\end{tabular}

\begin{tabular}{|l|l|l|l|}
\hline Vocabulary size & 2 & $\begin{array}{l}3.18 \\
61\end{array}$ & $\begin{array}{l}.796 \\
43\end{array}$ \\
\hline $\begin{array}{l}\text { In-depth vocabulary } \\
\text { knowledge }\end{array}$ & 2 & 3.68 & .736 \\
& & 14 & 34 \\
\hline
\end{tabular}

\subsubsection{Vocabulary learning strategies}

We can see from Table 3.2 that the most frequently used category is cognitive strategy, and the least frequently used one is social/ affective strategy, with meta-cognitivestrategy inbetween.

Table.3.2: Strategy use at three levels

\begin{tabular}{|l|c|l|c|}
\hline Categories & $\begin{array}{l}\text { N of } \\
\text { Items }\end{array}$ & Mean & SD \\
\hline $\begin{array}{l}\text { Meta-cognitive } \\
\text { Strategies }\end{array}$ & 24 & 2.8826 & .57507 \\
\hline Cognitive Strategies & 59 & 3.0970 & .68419 \\
\hline $\begin{array}{l}\text { Social/affective } \\
\text { Strategies }\end{array}$ & 11 & 2.8363 & .57652 \\
\hline
\end{tabular}

In order to obtain a further insight into the overall pattern of the vocabulary learning strategies used by the students, we will investigate the use of meta-cognitive, cognitive and social/ affective strategies separately.

Table.3.3: Strategy use at meta-cognitive level

\begin{tabular}{|l|r|c|c|}
\hline Strategies & $\begin{array}{l}\text { N of } \\
\text { Items }\end{array}$ & Mean & SD \\
\hline $\begin{array}{l}\text { Plan Making } \\
\text { \&Implementing }\end{array}$ & 5 & 3.0621 & .71131 \\
\hline Selective Attention & 7 & 3.0656 & .66587 \\
\hline Learner Autonomy & 7 & 2.8457 & .52775 \\
\hline Reviewing \&Testing & 5 & 2.5971 & .43809 \\
\hline
\end{tabular}

As we can see from Table 3.3, the most frequently used strategies at meta-cognitive level are selective attention strategies.What follow immediately are plan making \& and plan implementing strategies. However, learner autonomy strategies andreviewing \&testing strategies are not frequently used. 
Table.3.4: Strategy use at cognitive level

\begin{tabular}{|c|c|c|c|}
\hline $\begin{array}{l}\text { Categories and } \\
\text { strategies }\end{array}$ & $\begin{array}{c}\text { N } \quad \text { of } \\
\text { Item }\end{array}$ & Mean & SD \\
\hline Memorization & 30 & 3.0906 & .66116 \\
\hline Repetition & 8 & 3.0532 & .71912 \\
\hline Association & 3 & 3.4723 & .69644 \\
\hline Imagery & 4 & 2.8794 & .72315 \\
\hline Word Formation & 4 & 2.9867 & .73723 \\
\hline Grouping & 7 & 2.8660 & .66842 \\
\hline Contextualization & 4 & 3.2149 & .62095 \\
\hline Guessing & 9 & 3.3652 & .73498 \\
\hline Dictionary Use & 12 & 3.1268 & .49102 \\
\hline Note Taking & 8 & 2.8865 & .68706 \\
\hline
\end{tabular}

Table 3.4 showed that among all the cognitive strategies, guessing strategies are most frequently used, which are followed by dictionary use strategies and memorization strategies. Note-taking strategies are the least frequently used one. Among the subcategories of memorization strategies, association strategies, contextualization strategies, and repetition strategies are frequently used, while word formation strategies, imagery strategies, groupingstrategies are seldom used by the students. When we take all the specific strategies at the cognitive level into consideration, the frequently used strategies are association strategies, guessing strategies, contextualization strategies, dictionary use strategies, repetition strategies. Comparatively speaking, word formation strategies, note-taking strategies, imagery strategies, groupingstrategiesare not favored by subjects investigated.

Table.3.5: Strategy use at social/affective level

\begin{tabular}{|l|l|l|c|}
\hline $\begin{array}{l}\text { Categories and } \\
\text { strategies }\end{array}$ & $\begin{array}{l}\text { No of } \\
\text { items }\end{array}$ & $\mathrm{n}$ & Mea \\
\hline Social/Affective & 11 & 2.8363 & .57652 \\
\hline Social strategy & 5 & 2.6083 & .53181 \\
\hline $\begin{array}{l}\text { Affective } \\
\text { strategy }\end{array}$ & 6 & 3.0844 & .63239 \\
\hline
\end{tabular}

We can see from Table 3.5, affective strategies are frequently employed by participants, but social strategies are not favored so much by them.

We have listed the use frequency of meta-cognitive strategies, cognitive strategies and social/ affective strategies as a whole, now we will have a look at the use frequency of each specific strategy of eachcategorys eparately.

Table.3.6: The use frequency of each strategy

\begin{tabular}{|l|c|l|l|}
\hline $\begin{array}{l}\text { Categories and } \\
\text { strategies }\end{array}$ & Nof items & Mean & SD \\
\hline Meta-cognitive & 24 & 2.8826 & .57507 \\
\hline $\begin{array}{l}\text { Plan Making \& } \\
\text { Implementing }\end{array}$ & 5 & 3.0621 & .71131 \\
\hline Selective Attention & 7 & 3.0656 & .66587 \\
\hline Learner Autonomy & 7 & 2.8457 & .52775 \\
\hline Reviewing \&Testing & 5 & 2.5971 & .43809 \\
\hline Cognitive & 59 & 3.0970 & .68419 \\
\hline Memorization & 30 & 3.0906 & .66116 \\
\hline Repetition & 8 & 3.0532 & .71912 \\
\hline Association & 3 & 3.4723 & .69644 \\
\hline Imagery & 4 & 2.8794 & .72315 \\
\hline Word Formation & 4 & 2.9867 & .73723 \\
\hline Grouping & 7 & 2.8660 & .66842 \\
\hline Contextualization & 4 & 3.2149 & .62095 \\
\hline Guessing & 9 & 3.3652 & .73498 \\
\hline Dictionary Use & 12 & 3.1268 & .49102 \\
\hline Note-Taking & 5 & 2.8865 & .68706 \\
\hline Social/Affective & 11 & 2.8363 & .57652 \\
\hline Social & 5 & 2.6083 & .53181 \\
\hline Affective & 3.0844 & .63239 \\
\hline
\end{tabular}

From the list above we can see that the frequently used ones are association strategies, guessing strategies, contextualization strategies, dictionary use strategies, affective strategies, selective attention strategies, plan making \&implementing strategies, repetition strategies. The 
occasionally used ones are word formation strategies, note-taking strategies, imagery strategies, grouping strategies, learner autonomy strategies, social strategies, and reviewing \&testing strategies.

\section{CONCLUSION AND PEDAGOGICAL IMPLICATIONS}

\subsection{Conclusion}

The results of the study indicate that most learners hold the belief that vocabulary should be learned in context and use. They do not favor the idea that words should be memorized. Most of them are aware that learning a word means learning its various types of knowledge rather than simply knowing its form and basic meanings. The learning beliefs do have influence on theachievement of the students in vocabulary acquisition. The belief that words should be learned in context \& use has significant positive correlation with the VS and DVK scores whereas the belief that words should be memorized hasnegative relation with the VS and DVK scores. The belief that vocabulary size is the main goal in English learning is positively related with the VS scores whereas this belief is negatively correlated with the DVK scores. The belief that great emphasis should be put on in-depth knowledge has significant positive relation with both the DVK scores and the VS scores.

Learners tend to use a wide range of meta-cognitive, cognitive, and social/affective learning strategies in the vocabulary learning.However, the use frequency is not high.Among the meta-cognitivestrategies, plan making \&implementing strategies and selective strategies are frequently employed while learner autonomy strategies and reviewing \&testing strategies are not frequently used. The participants use a wide range of cognitive strategies. In terms of specific cognitive strategies, the most frequently used ones are association strategies, guessing strategies, contextualization strategies, dictionary use strategies and repetition strategies; the least frequently used ones are word formation strategies, note-taking strategies, imagery strategies, and grouping strategies. The participants frequently use affectivestrategies in the process of vocabulary learning. They show the tendency to control their emotions and know how to encourage themselves when they are faced with difficulties. However, they seldom involve in operating with other people. They prefer to learn independently.

Students'strategy use is generally theresult of their previous learning experience, the influence of their teachers' teaching methods, the Chinese traditional culture, oriental student's characters, and the limitations of learning environment. Firstly, students are more likely to use the strategies that they are familiar with and their teachers often adopt in class, suchas association strategies, guessing strategies, contextualization strategies, dictionary use strategies, selective attention strategies, plan making \& implementing strategies, repetition strategies, and affective strategies. Secondly, students do not like to use the strategies that are difficult to use or demand de liberate effort, such as imagery strategies, note-taking strategies and grouping strategies. Thirdly, students prefer to learn on their own; therefore, they seldom use social strategies. Finally, students can concentrate on their learning, possess self-confidence, and encourage themselves when faced with difficulties.

As far as the correlation between vocabulary learning strategies employed by the students and the scores of VS and DVK tests, the results indicate that most strategies are significantly correlated with the two scores. At meta-cognitive level, plan making \& plan implementing strategies, learnerautonomystrategies, and reviewing\& testing strategies all have significant positivecorrelation with both the VS scores and DVK scores. Selective attention strategies have significant positivecorrelation with the DVK scores.

The correlation between cognitive vocabulary learning strategiesand the scores of VS and DVK tests is comparatively complicated.The strategies that involve deep processing are morelikely to lead to better retention. 
Guessing strategies, contextualization strategies and association strategies involve in deep level processing of the target words; therefore, they are helpful for both the quality and quantity of vocabulary knowledge. Similarly, imagery strategies have significant positive correlation with the DVK scores.However, repetition strategies, which involve mechanical memorization, are not helpful to vocabulary learning.

Groupings strategies and word formation strategies are helpful to enlarge vocabulary size. Grouping involves classifying or reclassifying words into meaningful groups, thus reducing the number of unrelated elements. Similarly, with the help of word formation knowledge, the task of knowing the primary meaning of some new words and furtherremember them becomes much easier.

Note-taking strategies have significant positive correlation with both the VS scores and DVK scores, because the process of taking notes itself is one useful form of learning and the notes learners have taken can serve as good source of reference for later revision. Dictionary use is significantly correlated with the students' depth of vocabulary knowledge because it provides all-inclusive information of a word, as well as some good examples.

Affective strategies help to regulate emotions, and are, therefore, helpful to both vocabulary size and in-depth vocabulary knowledge. Social strategies are not significantly correlated with learning achievements.It is possible that students do not use this strategy effectively.

\subsection{Pedagogical Implications}

From the analysisabove we can see that a majority of vocabulary learningstrategiesare both helpful for enlarging vocabulary size and deepening in-depth vocabulary knowledge, which is consistent with the findings of a lot of previous studies. However, the present study also shows that the frequency of strategy use is not high and students only favor some of the strategies and neglect others. The English teachers should get some implication from this study. In their teaching practice, most teachers tend to focus their attention on teaching thelanguage itself and neglect strategy training. Therefore, more training should be conducted to enhance students'co-consciousness of strategy use. In addition, when the teachers conduct strategy training, they should place more emphas is on the strategies that are positively correlated with vocabulary acquisition but the students seldom use, for example, reviewing \&testing strategies and learner autonomy strategies at meta-cognitive level, word formation strategies, grouping strategies, note-taking strategies at cognitive level, and social strategies at social/affective level. Meanwhile, the teachers should devise a series of activities to help students to learn how to use particular strategies which are useful for vocabulary learning but the students are not familiar with or feel difficult to use, for example, imagery strategy.

\subsection{Limitations and recommendations}

Firstly, the investigation only involves structured questionnaire only. If more investigation techniques, such as structured interview and think-aloud, are employed, the study should be more comprehensive. Secondly, due to the constraints of time and energy, only 94 students are investigated concerning the strategy use and the performance in vocabulary size and in-depth vocabulary knowledge tests, which is far from a thorough exploration. If time and energy permits, mo re subjects should be included in future work. Thirdly, due to the large number of vocabulary learning strategies and the limited length of the paper, only rough description of each specific strategy is made. In future studies, more detailed and refined description of each strategy will be provided.

\section{REFERENCES}

[1] Wilkins, D. (1972).Linguistics and Language Teaching . London: Edward Arnold.

[2] McCarthy, M. J. (1990).Vocabulary. Oxford: Oxford University Press.

[3] Nation, P. (1990). Teaching and Learning Vocabulary. New York: Newbury House Publishers. 
[4] Laufer, B. (1992). Reading in a foreign language: How does L2 lexical knowledge interact with the learner's general academicability? Journal of Research in Reading, 15, 95-103.

[5] Read, J. (2000). Assessing Vocabulary.Cambridge: Cambridge University Press.

[6] Gu, Yongqi \& Johnson, R. K. (1996). Vocabulary learning strategies and language learning outcomes, Language Learning, 46, 643-679.

[7] Ellis, R. (1994). The Study of Second Language Acquisition. Oxford: Oxford University Press.

[8] Oxford, R. (1990). Language Learning Strategies: What Every Teacher Should Know.New York: Newbury House Publishers.

[9] Wolter, B. (2001). Comparing the L1 and L2 mental lexicon: A depth of individual word knowledge model, Studies in Second Language Acquisition, 23, 41-69.

[10] Leeke, P. \& Shaw, P. (2000). Learners' independent records of vocabulary, System, 28,271-289.

[11] Cohen, A. D. (2000). Strategies in Learning and Using a Second Language. Beijing: Foreign Language Teaching and Research Press.

[12] Wesche, M. B. \& Paribakht, T. S.(2000). Reading-based exerc ise in second language vocabulary learning: An introspective study.Modern Language Journal, 84, 196-210. 